\title{
Clinical Practice Competence and its Associated Factors Among Midwifery and Nursing Students at Dire Dawa Health Sciences Colleges, East Ethiopia, 2020
}

\author{
Mickiale Hailu' \\ Mengstu Welday ${ }^{2}$ \\ Abera Haftu ${ }^{2}$ \\ Daniel Tadesse (iD) \\ Taddese Weldeamanel ${ }^{1}$ \\ Bezabih Amsalu' \\ Alemu Guta (D)' \\ Nigus Kassie' \\ Alekaw Sema' \\ Aminu Mohammed' \\ Neil Abdurashid (D') \\ Yonatan Solomon (D) \\ Feyso Bati (iD) \\ Meklit Girma ${ }^{2}$ \\ Yitagesu Sintayehu (D) \\ Yalelet Belay' \\ Sewmehon Amsalu' \\ 'Midwifery Department, Dire Dawa \\ University, Dire Dawa, Ethiopia; ${ }^{2}$ College \\ of Health Sciences, Department of \\ Midwifery, Mekelle University, Mekelle, \\ Ethiopia
}

Background: Competence is defined as the ability to perform a task with desirable outcomes. Globally, an estimated 530,000 women and 2 million newborns die each year, because of no access to competent health professionals. But half of those deaths can be prevented with competent health professionals. However, the existing literature shows that most new graduates have a lack of competence in the clinical environment, none of them have assessed whether student or preceptor factors have an association with clinical competence or not. So, this study is crucial to fill data scarcity.

Objective: To determine the clinical practice competence and associated factors among midwifery and nursing students at Dire Dawa.

Methods: Institutional cross-sectional study was conducted on nursing and midwifery students from February 10/2020 to February 30/2020. Self-administered questionnaires were given to 318 students through a simple random lottery. Multivariate logistic regression analysis was done for variables with a p-value $<0.2$ in binary logistic regression. The odds ratio was used to measure the degree of association.

Results: Only $19.2 \%$ are clinically competent. Students who were oriented about assessment methods were 4 times more likely competent [AOR $=4.096 \mathrm{p}$-value 0.035]. Students who have staff encouragement and have preceptors were 5 times [AOR $=4.900 \mathrm{p}$-value 0.12 ] and 11 times $[\mathrm{AOR}=11.052 \mathrm{p}$-value 0.00$]$ more likely competent, respectively. Confident students were 4 times more likely competent [AOR $=4.460$, p-value 0.005 ].

Conclusion: The prevalence of clinical competence is very minimal. This is due to assessment methods orientation, staff encouragement, clinical preceptor support and students' confidence. This finding contributes to the federal ministry of health should work closely with teaching institutions, health facilities, and other stakeholders to overcome those gaps.

Keywords: competence, clinical practice, clinical practice competence

\section{Background}

The word competence was derived from the Latin word "competentia" which means capability and permission. Later, the concept of competence and its application in the Nursing field was described by Benner (1984) in which Nursing competence as the ability to perform a task with desirable outcomes.

The demographic changes of the population increased technological advancements, and increased prevalence of chronic illnesses highlighted the necessity of competent graduating students. Meanwhile, the existing evidence indicated that 
globally there is a shortage of competent health-care providers. Globally, an estimated 530,000 women and 2 million newborns die yearly due to a shortage of competent health professionals. Besides, WHO has recently concluded that almost half of all deaths can be prevented with competent Midwives. ${ }^{2-5}$

In Ethiopia, the health-care system is facing a serious shortage of competent health workforces. This is evidenced by the World Bank report that revealed that about $70 \%$ of health-care providers were with poor competencies. These inadequate competencies among health professionals were considered as a major factor for the report of low satisfaction of clients among different health facilities of Ethiopia. ${ }^{6,7}$

A study conducted in Hawassa and Amhara Region University shows that the overall prevalence of clinical competence was only $25.2 \%$ and $33.6 \%$, respectively. This is potentially a challenge in Ethiopia, given high student enrollment, a shortage of qualified faculty, resource constraints, and questionable clinical competence of students at clinical training sites. ${ }^{6,8,9}$

Studies from different part of the globe also identified factors associated with students' clinical competence such as Gender influence achievement of specific competencies in which male students were scored high performance than females, instructors' constructive feedback during clinical practice, providing orientation about the objective of clinical practice, using a checklist for assessment, staff encouragement during clinical practice, clinical preceptor ship.

Even though the previous studies done in Ethiopia suggested that most new bachelor graduates have a lack of competence in the clinical environment, none of them have assessed whether student or preceptor factors have association with clinical competence or not. ${ }^{6,8,10}$

The results of the study will be useful for overcoming the factors that hinder the clinical competence of students by policymakers, higher officials, NGOs, the ministry of health, teaching institutions and other stakeholders.

\section{Methods}

\section{Study Setting and Design}

An institutional cross-sectional study was conducted among nursing and midwifery bachelor students at health science schools in Dire Dawa city from February 10 to 30/ 2020. Self-administered questionnaires were given to 318 students from Dire Dawa University and Rift valley health Science College through a simple random lottery.

\section{Study Population and Sampling Procedure}

All Bachelor of Science in Midwifery and Nursing students who were attending Dire Dawa Health Science Colleges were the source population. A single population proportion formula $[n=(z \alpha / 2) 2 p(1-p) / d 2]$ was used to calculate the sample size with the assumption of p-value $0.252,95 \%$ confidence level, $5 \%$ margin of error and $10 \%$ of non-response rate.

Overall, we recruited a total of 318 respondents. One hundred and thirty-seven students from Dire Dawa University and 181 students from Rift Valley University were allocated proportionally based on the number of students in each school.

All 2nd year and above students from Bachelor of Science in Midwifery and Nursing were taken as inclusion criteria while those who were critically ill during the data collection period and those who discontinued their study due to withdrawal were excluded from the study.

\section{Data Collection Tool and Procedures}

A structured questionnaire was used after reviewing important literature on the problem under the study. ${ }^{6,8,10-13}$

The questionnaire was designed to obtain information on the main variables which is categorized under 4 sections. A total number of 58 items were included in the data collection tool (10 Socio-demographic data, 15 Clinical practice competence assessment, 19 Clinical practicerelated, 6 Preceptor related and 8 Student related)

Clinical competence and clinical practice-related questions were organized through statements with a Likert measurement scale while the rest of the questions includes a "YES" or "NO" alternative and some other relevant alternative responses.

The data collectors were 2 BSC nurses and 2 MSC midwives. A pre-test was conducted by taking $10 \%$ of the sample size in Haramaya University and Harar health Science College which was under a similar setup. Appropriate modifications were made after analyzing the pretest result before the actual data collection. Data quality was assured by giving training and appropriate supervision for data collectors. The overall supervision was carried out by the principal investigator. The collected data were also cross-checked on a daily basis for its consistency and completeness.

\section{Data Processing and Analysis}

The internal consistency of Likert scale questions was measured by Cronbach's alpha and it was reported 0.928 which is above the recommended value of Cronbach's alpha which is 0.70 . 
The collected data were entered into Epi Data version 4.2 and exported to SPSS version 20 for data processing and analysis. Descriptive statistics like percentage, mean and standard deviation were done. Both bivariate and multivariate logistic regression analyses were computed to identify associated factors. Odds ratio along with $95 \%$ CI was computed to ascertain the association between independent and outcome variables. Variables that have a p-value of $<0.2$ at bivariate analysis were included in multivariate logistic regression to control possible confounding factors. Statistical tests at a p-value of $<0.05$ were considered statistically significant.

The model fit was checked by Hosmer and Lemeshow Test which is the most reliable test of model fit available in SPSS. Hence, the chi-square value for the Hosmer-Lemeshow Test is 4.079 with a significance level of 0.85 . This value is greater than 0.05 , therefore indicating the goodness of model fit.

\section{Results}

\section{Socio-Demographic Characteristics of Respondents}

A total of 318 students have participated in the study giving a response rate of $100 \%$. As shown in Table 1, the age ranged from 18 to 29 with a mean age of 21.04 years $(\mathrm{SD}+21.04)($ Table 1$)$.

\section{Clinical Practice Competence of Midwifery and Nursing Students at Dire Dawa Health Science Colleges}

As Figure 1 shows, from 318 students, the overall clinical practice competence of the study participant was $19.2 \%$ (Figure 1).

Besides, there was a slight difference in clinical practice competence of the study participants in terms of type institution, year of study, and departments (Figure 2).

Regarding the type of institution in which students attend and department of study participants $18.2 \%$ of Dire Dawa University students and $20.5 \%$ of Midwifery students were clinically competent, respectively.

\section{Clinical Instructor Factors Response of Midwifery and Nursing Students}

As Table 2 shows, half of the participants agreed on clinical instructor orient about the objective of clinical practice and
Table I Socio-Demographic Characteristics of Midwifery and Nursing Students at Dire Dawa Health Science Colleges

\begin{tabular}{|c|c|c|c|}
\hline \multicolumn{2}{|c|}{ Characteristics } & \multirow{2}{*}{$\begin{array}{r}\text { Frequency } \\
137\end{array}$} & \multirow{2}{*}{$\begin{array}{r}\text { Percentage \% } \\
43.1\end{array}$} \\
\hline University & Dire Dawa & & \\
\hline & Rift valley & 181 & 56.9 \\
\hline \multirow[t]{5}{*}{ Religion } & Orthodox & 159 & 50.0 \\
\hline & Muslim & 122 & 38.4 \\
\hline & Protestant & 34 & 10.7 \\
\hline & Catholic & 3 & 0.9 \\
\hline & Others & & - \\
\hline \multirow[t]{4}{*}{ Marital status } & Single & 296 & 93.1 \\
\hline & Married & 20 & 6.3 \\
\hline & Widowed & 1 & 0.3 \\
\hline & Divorced & I & 0.3 \\
\hline \multirow[t]{5}{*}{ Ethnicity } & Oromo & 136 & 42.8 \\
\hline & Amhara & 97 & 30.5 \\
\hline & Somali & 53 & 16.7 \\
\hline & Tigray & 13 & 4.1 \\
\hline & SNNPS & 19 & 6.0 \\
\hline \multirow[t]{2}{*}{ Residence } & Urban & 254 & 79.9 \\
\hline & Rural & 64 & 20.1 \\
\hline \multirow[t]{2}{*}{ Departments } & Midwifery & 151 & 47.5 \\
\hline & Nursing & 167 & 52.5 \\
\hline \multirow[t]{3}{*}{ Year of study } & 2nd year & 126 & 39.6 \\
\hline & 3rdyear & 111 & 34.9 \\
\hline & 4th year & 81 & 25.5 \\
\hline \multirow{5}{*}{$\begin{array}{l}\text { Father } \\
\text { educational } \\
\text { status }\end{array}$} & Unable to write and read & 24 & 7.5 \\
\hline & Able to write and read & 86 & 27.0 \\
\hline & Primary (I-8) & 40 & 12.6 \\
\hline & Secondary (9-12) & 52 & 16.4 \\
\hline & Degree and above & 116 & 36.5 \\
\hline \multirow{5}{*}{$\begin{array}{l}\text { Mother } \\
\text { educational } \\
\text { status }\end{array}$} & Unable to write and read & 32 & 10.1 \\
\hline & Able to write and read & 91 & 28.6 \\
\hline & Primary (I-8) & 47 & 14.8 \\
\hline & Secondary (9-12) & 68 & 21.4 \\
\hline & Degree and above & 80 & 25.2 \\
\hline
\end{tabular}




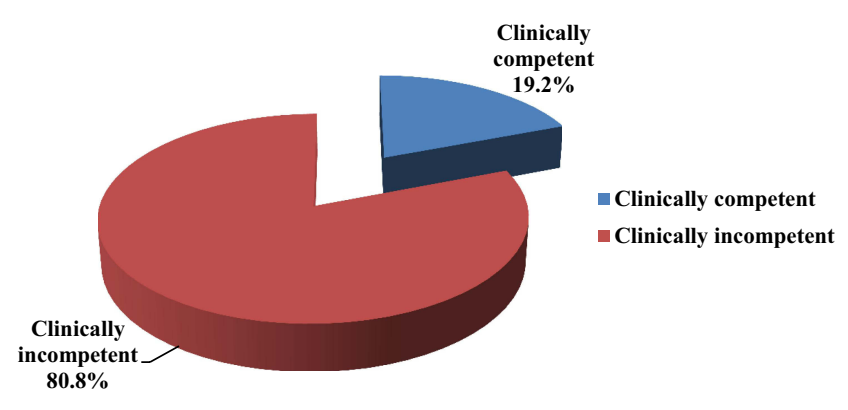

Figure I Clinical practice competencies of students.

$21.1 \%$ of them were neutral regarding clinical instructor provides logbook during clinical practice. $46.5 \%$ of the participants agreed that the clinical instructor provides constructive feedback and $30.5 \%$ of the participants disagreed on clinical instructor show clinical procedure (Table 2).

\section{Clinical Practice Environment Factors Response}

As shown in Table 3, on the clinical practice environment dimension, the lowest recorded score was for the statement "Clinical placement has a room for joint meetings" While the highest score was for "Clinical practice environment has sufficient wards".

\section{Assessment Method Factors Response}

As shown in Tables 4, 167 (52.5\%) of participants agreed. About $160(50.3 \%)$ of the participants agreed on the instructor use checklist to assess the performance of students and 77 (24.2\%) of them disagreed that instructors' orientation about assessment methods during clinical practice (Table 4).

\section{Preceptor Factors Response}

As Figure 3 shows, the Majority of the respondents agreed that the preceptor identifies students' learning needs and the minority of the participants have disagreed that the preceptor has good clinical skills during clinical practice (Figure 3).

\section{Student Factor Response}

Regarding absenteeism during clinical practice 90 (28.3\%) were absent from clinical practice without permission, out of the 44 (48.9\%) were absent once, 34 (37.8\%) were twice and $12(13.3 \%)$ were three times and above (Table 5).

\section{Factors Associated with Clinical Practice Competence}

As Table 6 shows, in bivariate analysis instructors orient the objective of the clinical practice, instructors show clinical procedure, instructors provide feedback, conducive clinical placement and instructors use a checklist to assess performance were found to be significantly associated factors with students' clinical practice competence.

In multivariate analysis, Staff encourages students, Instructors orient about assessment methods, having preceptors in your clinical practice and Confident during performing procedures were found to be significantly associated factors with students' clinical practice competence.

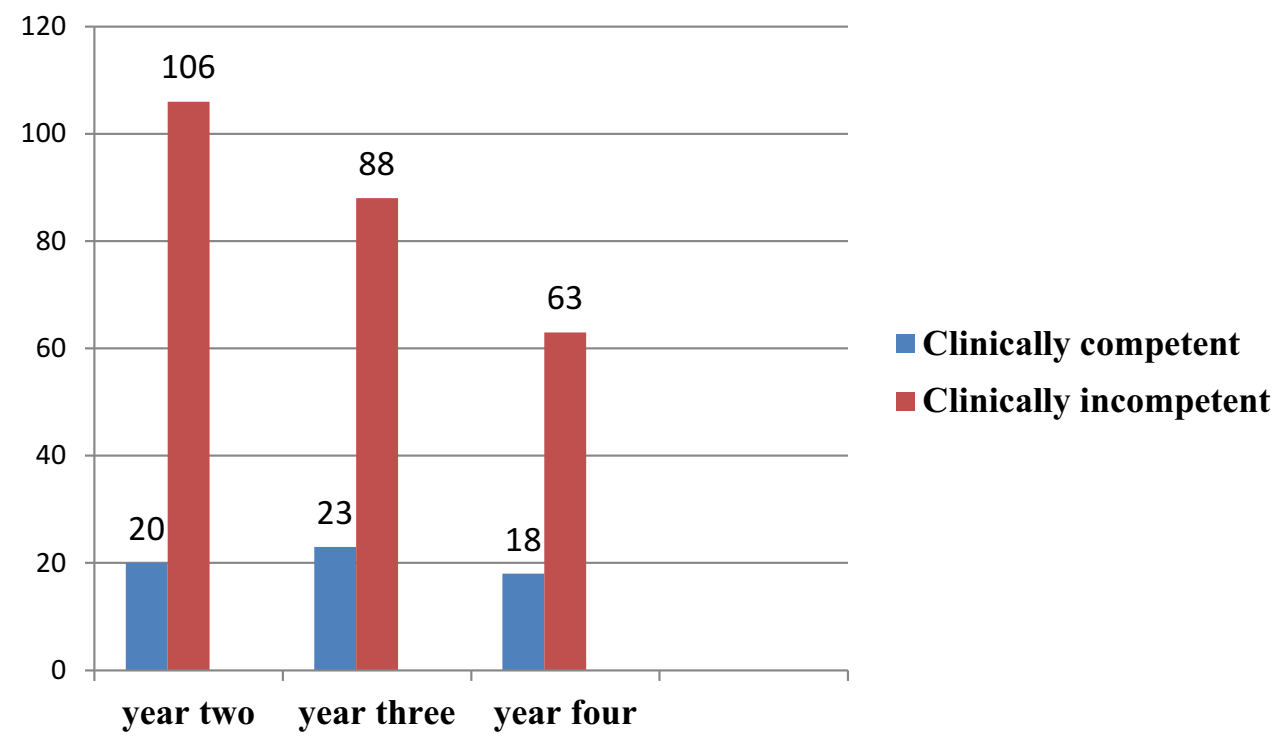

Figure 2 Clinical practice competencies by year of study. 
Table 2 Clinical Instructor Characteristics Response of Midwifery and Nursing Student at Dire Dawa Health Science Colleges

\begin{tabular}{|l|l|l|l|l|l|l|l|l|l|}
\hline \multicolumn{2}{|l}{ Clinical Instructor Factor } & \multicolumn{2}{l}{ Agree } & Neutral & \multicolumn{2}{l|}{ Disagree } & Mean & SD \\
\cline { 3 - 10 } & Frequency & $\%$ & Frequency & $\%$ & Frequency & $\%$ \\
\hline 1 & Provide logbook & 137 & 43.1 & 69 & 21.7 & 112 & 35.2 & 2.07 & 0.88 \\
\hline 2 & Orient the objective of clinical practice & 159 & 50 & 67 & 21.1 & 92 & 28.9 & 2.21 & 0.86 \\
\hline 3 & Spent enough time on clinical site & 138 & 43.4 & 82 & 25.8 & 98 & 30.8 & 2.12 & 0.85 \\
\hline 4 & Use different learning methods & 158 & 49.7 & 76 & 23.9 & 84 & 26.4 & 2.23 & 0.84 \\
\hline 5 & Show clinical procedure & 141 & 44.3 & 80 & 25.2 & 97 & 30.5 & 2.13 & 0.85 \\
\hline 6 & Provides constructive feedback & 148 & 46.5 & 79 & 24.8 & 91 & 28.6 & 2.17 & 0.84 \\
\hline
\end{tabular}

Table 3 Clinical Practice Environment Characteristics of Midwifery and Nursing Student at Dire Dawa Health Science Colleges

\begin{tabular}{|c|c|c|c|c|c|c|c|c|c|}
\hline \multicolumn{2}{|r|}{ Clinical Practice Environment Factors } & \multicolumn{2}{|l|}{ Agree } & \multicolumn{2}{|l|}{ Neutral } & \multicolumn{2}{|l|}{ Disagree } & \multirow{3}{*}{$\begin{array}{l}\text { Mean } \\
2.08\end{array}$} & \multirow{3}{*}{$\begin{array}{l}\text { SD } \\
0.84\end{array}$} \\
\hline & & Frequency & $\%$ & Frequency & $\%$ & Frequency & $\%$ & & \\
\hline 1 & Clinical practice environment is conducive & 126 & 39.6 & 92 & 28.9 & 100 & 31.4 & & \\
\hline 2 & Clinical practice environment has sufficient cases & 127 & 39.9 & 84 & 26.4 & 107 & 33.6 & 2.06 & 0.85 \\
\hline 3 & Clinical practice environment has sufficient material & 131 & $4 I .2$ & 77 & 24.2 & 110 & 34.6 & 2.07 & 0.86 \\
\hline 4 & $\begin{array}{l}\text { Clinical practice environment has meet objectives of } \\
\text { clinical practice }\end{array}$ & $|3|$ & 41.2 & 77 & 24.2 & 110 & 34.6 & 2.07 & 0.86 \\
\hline 5 & Clinical practice environment has sufficient wards & 140 & 44 & 80 & 25.2 & 98 & 30.8 & 2.13 & 0.85 \\
\hline 6 & Clinical placement has a room for joint meetings & 122 & 38.4 & 99 & 31.1 & 97 & 30.5 & 2.07 & 0.82 \\
\hline 7 & $\begin{array}{l}\text { Staff allows students to perform tasks during clinical } \\
\text { practice }\end{array}$ & 132 & 41.5 & 96 & 30.2 & 90 & 28.3 & 2.13 & 0.82 \\
\hline 8 & Staff encourages students during clinical practice & 137 & 43.1 & 65 & 20.4 & 116 & 36.5 & 2.06 & 0.89 \\
\hline
\end{tabular}

Table 4 Assessment Method Characteristics of Midwifery and Nursing Student at Dire Dawa Health Science Colleges

\begin{tabular}{|c|c|c|c|c|c|c|c|c|c|}
\hline \multicolumn{2}{|r|}{ Assessment Method Factors } & \multicolumn{2}{|l|}{ Agree } & \multicolumn{2}{|l|}{ Neutral } & \multicolumn{2}{|l|}{ Disagree } & \multirow{3}{*}{$\begin{array}{l}\text { Mean } \\
2.24\end{array}$} & \multirow{3}{*}{$\begin{array}{l}\text { SD } \\
0.81\end{array}$} \\
\hline & & \multirow{2}{*}{$\begin{array}{l}\text { Frequency } \\
155\end{array}$} & \multirow{2}{*}{$\%$} & \multirow{2}{*}{$\begin{array}{l}\text { Frequency } \\
86\end{array}$} & \multirow{2}{*}{$\begin{array}{l}\% \\
27.0\end{array}$} & \multirow{2}{*}{$\begin{array}{l}\text { Frequency } \\
77\end{array}$} & \multirow{2}{*}{$\begin{array}{l}\% \\
24.2\end{array}$} & & \\
\hline I & Instructors orient about assessment methods & & & & & & & & \\
\hline 2 & $\begin{array}{l}\text { Assessment method has a positive influence on clinical } \\
\text { practice }\end{array}$ & 144 & 45.5 & 95 & 29.9 & 79 & 24.8 & 2.20 & 0.81 \\
\hline 3 & Instructor uses continuous assessment methods & 167 & 52.5 & 82 & 25.8 & 69 & 21.7 & 2.30 & 0.80 \\
\hline 4 & Assessment methods address the three learning domain & 146 & 45.9 & 101 & 31.8 & 71 & 22.3 & 2.23 & 0.80 \\
\hline 5 & Instructor use checklist to assess the performance & 160 & 50.3 & 72 & 22.6 & 86 & 27 & 2.23 & 0.84 \\
\hline
\end{tabular}

Students who were oriented about the assessment methods were 4 times more likely competent than those who were not oriented [(AOR=4.096 $(1.104,15.196)]$. Students who were encouraged by clinical staff during clinical practice were 5 times more likely competent than those who were not encouraged $[(\mathrm{AOR}=4.900(1.433,17.380)]$. 


\section{Yes \% of Perceptor Factor}

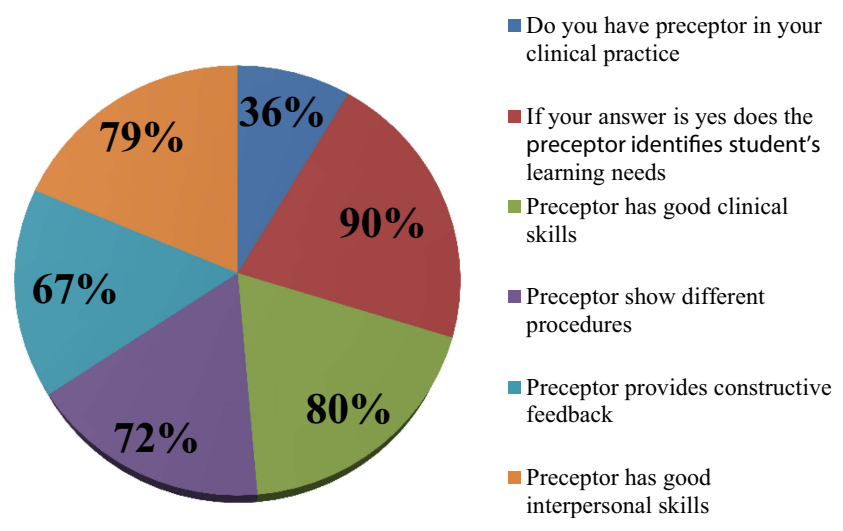

Figure 3 Preceptor factor characteristics of midwifery and nursing student.

Students who have clinical preceptor support during clinical practice were 11 times more likely competent than those who have not clinical preceptor support [(AOR $=11.052$ (4.377, 27.908)].

Students who were confident during conducting a procedure were 4 times more likely competent than those who were not confident during conducting a procedure $[(\mathrm{AOR}=4.460(1.586,12.541)]$ (Table 6).

\section{Discussion}

Regarding students' clinical practice competence, only $19.2 \%$ of students are clinically competent during clinical practice. This finding is almost similar to the finding of a study conducted among Nursing and Midwifery students at Hawassa University, which is $23.2 \%$ and $22.8 \%$, respectively (9.)
In contrast, it is lower as compared with the finding of $33.6 \%$ study done among graduating Nursing students attending at Amhara Region Universities. This discrepancy might be due to the difference in study setting and characteristics of study participants. The previous study was conducted in six institutions and the study participants were only graduating Nursing students. ${ }^{8}$

The result of this study was also lower as compared with a study conducted in Finland, which was $66.7 \%$. This might be due to the difference in the socio-economic status of study participants and in the curriculum of the nation. ${ }^{14}$

In this study, students who had been oriented about the assessment method during clinical practice were more likely competent than those who did not get the orientation about the assessment method. This finding is supported by another study conducted in Finland and Ethiopia that indicates that giving orientation about the clinical assessment methods contributes to students' clinical practice competence. $^{10,14}$

The above finding was inconsistent with a study conducted at Hawassa University that was not significantly associated with the clinical practice competence of students. This variation might be due to the difference in characteristics of the respondent and study design. The previous study was conducted in one governmental institution and the study participants were all health science students with mixed study design but the current study was conducted in a private and governmental institutions and the study participants were Midwifery and Nursing students with the quantitative cross-sectional study. ${ }^{6}$

Students who have clinical preceptor support during clinical practice were more likely to be competent than

Table 5 Student Factor Characteristics of Midwifery and Nursing Student at Dire Dawa Health Science Colleges

\begin{tabular}{|c|c|c|c|c|c|}
\hline \multicolumn{2}{|r|}{ Student Factor During Clinical Practice } & \multicolumn{2}{|l|}{ Yes } & \multicolumn{2}{|l|}{ No } \\
\hline & & \multirow{2}{*}{$\begin{array}{l}\text { Frequency } \\
276\end{array}$} & \multirow{2}{*}{$\frac{\%}{86.8}$} & \multirow{2}{*}{$\begin{array}{l}\text { Frequency } \\
42\end{array}$} & \multirow{2}{*}{$\frac{\%}{13.2}$} \\
\hline I & Having a good relationship with team members & & & & \\
\hline 2 & Having good information exchange habit with team members & 252 & 79.2 & 66 & 20.8 \\
\hline 3 & I was motivated and eager to learn & 244 & 76.7 & 74 & 23.3 \\
\hline 4 & I was confident during conducing procedure & 217 & 68.2 & 101 & 31.8 \\
\hline 5 & Absent from clinical practice without permission & 90 & 28.3 & 228 & 71.7 \\
\hline 6 & I was punctual during my clinical practice & 234 & 73.6 & 84 & 26.4 \\
\hline 7 & My parent economic status affected my clinical practice & 214 & 67.3 & 104 & 32.7 \\
\hline
\end{tabular}


Table 6 Bivariate and Multivariate Analysis Result for Clinical Practice Competence and Associated Factors Among Midwifery and Nursing Students at Dire Dawa Health Science Colleges

\begin{tabular}{|c|c|c|c|c|c|c|}
\hline \multicolumn{2}{|l|}{ Variables } & \multicolumn{2}{|c|}{ Clinical Practice Competence } & \multirow{3}{*}{$\begin{array}{c}\text { COR }(95 \% \mathrm{CI}) \\
6.385(2.613,15.601)\end{array}$} & \multirow{3}{*}{$\begin{array}{c}\text { AOR }(95 \% \mathrm{CI}) \\
0.617(0.159,2.398)\end{array}$} & \multirow{3}{*}{$\begin{array}{c}\text { P-value } \\
0.486\end{array}$} \\
\hline & & \multirow{2}{*}{$\begin{array}{c}\text { Competent } \\
49(80.3 \%)\end{array}$} & \multirow{2}{*}{$\begin{array}{c}\text { Not Competent } \\
110(42.8 \%)\end{array}$} & & & \\
\hline Instructor orient the objective of the clinical practice* & Agree* & & & & & \\
\hline & Neutral & $6(9.8 \%)$ & $61(23.7 \%)$ & $1.410(0.434,4.580)$ & $0.219(0.80,2.207)$ & 0.305 \\
\hline & Disagree & $6(9.8 \%)$ & $86(33.5 \%)$ & 1 & 1 & 1 \\
\hline \multirow[t]{3}{*}{ Instructor show clinical procedure * } & Agree* & $49(80.3 \%)$ & $92(35.8 \%)$ & $8.078(3.298,19.787)$ & $2.839(0.663,12.147)$ & 0.160 \\
\hline & Neutral & $6(9.8 \%)$ & $74(28.8 \%)$ & $1.23(0.381,3.972)$ & $0.55(0.105,2876)$ & 0.479 \\
\hline & Disagree & $6(9.8 \%)$ & 91 (35.4\%) & 1 & 1 & 1 \\
\hline \multirow[t]{3}{*}{ Instructor provide feedback* } & Agree* & $49(80.3 \%)$ & 99 (38.5\%) & $7.012(2.862,17.176)$ & $2.399(0.604,9.537)$ & 0.214 \\
\hline & Neutral & $6(9.8 \%)$ & $73(28.4 \%)$ & $1.164(0.36,3.767)$ & $0.409(0.77,2.162)$ & 0.293 \\
\hline & Disagree & $6(9.8 \%)$ & 85 (33.1\%) & 1 & 1 & 1 \\
\hline \multirow[t]{3}{*}{ Conducive clinical placement* } & Agree* & $48(78.7 \%)$ & 78 (30.4\%) & $9.641(3.919,23.718)$ & $3.353(0.982,11.449)$ & 0.54 \\
\hline & Neutral & 7 (1 I.5\%) & 85 (33.1\%) & $1.29(0.417,3.991)$ & $0.668(0.153,2.909)$ & 0.591 \\
\hline & Disagree & $6(9.8 \%)$ & 94 (36.6\%) & 1 & 1 & I \\
\hline \multirow[t]{3}{*}{ Staff encourages student $* *$} & Agree** & $48(78.7 \%)$ & 89 (34.6\%) & $9.888(4.046,24.162)$ & $4.99(1.433,17.380)$ & 0.012 \\
\hline & Neutral & 7 (1 I.5\%) & $58(22.6 \%)$ & $2.213(0.711,6.890)$ & $3.405(0.751,15.435)$ & 0.112 \\
\hline & Disagree & $6(9.8 \%)$ & 110 (42.8\%) & 1 & 1 & 1 \\
\hline \multirow[t]{3}{*}{ Instructors orient about assessment methods*** } & Agree** & $49(80.3 \%)$ & $106(41.2 \%)$ & $5.47(2.225,13.447)$ & $4.096(1.104,15.196)$ & 0.035 \\
\hline & Neutral & $6(9.8 \%)$ & $80(31.1 \%)$ & $0.888(0.274,2.876)$ & $0.972(0.219,4.322)$ & 0.970 \\
\hline & Disagree & $6(9.8 \%)$ & 71 (27.6\%) & 1 & 1 & I \\
\hline \multirow[t]{3}{*}{ Instructors use checklist to assess performance* } & Agree* & $43(70.5 \%)$ & 117 (45.5\%) & $4.148(1.776,9.688)$ & $0.486(0.131,1.803)$ & 0.281 \\
\hline & Neutral & II (18\%) & 61 (23.7\%) & $2.035(0.745,5.559)$ & $0.953(0.236,3.847)$ & 0.946 \\
\hline & Disagree & 7 (I I.5\%) & 79 (30.7\%) & 1 & 1 & I \\
\hline \multirow[t]{2}{*}{ Having preceptor in your clinical practice** } & Yes** & 45 (73.8\%) & $70(27.2 \%)$ & $7.513(3.989,14.152)$ & II.052 (4.37,27.908) & 0.00 \\
\hline & No & $16(26.2 \%)$ & 187 (72.8\%) & 1 & 1 & I \\
\hline \multirow[t]{2}{*}{ Confident during performing procedure** } & Yes** & 52 (85.2\%) & 165 (64.2\%) & $3.222(1.518,6.835)$ & $4.46(1.586,12.54 \mid)$ & 0.005 \\
\hline & No & $9(14.8 \%)$ & 92 (35.8\%) & 1 & 1 & I \\
\hline
\end{tabular}

Notes: *Show statistically significant association in bivariate logistic regression. **Show statistically significant association in multivariate logistic regression.

those who have not clinical preceptor support. This finding is similar to the study conducted in Indonesia, Ghana and Pakistan. ${ }^{13,15,16}$

However, the above was inconsistent with a study done in Alberta faculty Nursing, Canada that stated that the workload of clinical preceptors resulted in a negative impact on the clinical competency of students. This variation may be due to the difference in the health system policy and curriculum of the nations. ${ }^{17}$
Students who were confident during conducting procedures during clinical practice were more likely to be competent than those who were not confident. This finding is supported by a study conducted in Indonesia and Sweden. This may be due to the reason that self-confidence is a key component of effective clinical competence. ${ }^{15,18}$

The above finding was inconsistent with a crosssectional study done in Tanzania, in which the confidence of Nursing students was not significantly associated with 
clinical practice competence. This variation might be due to the difference in sample size and the characteristics of the study participants in which the sample size was 208 and the study participants were Diploma Nursing Students. ${ }^{12}$

\section{Research Limitation}

This research is done using quantitative design. If this research would be supported by Qualitative study design, it could help to build in-depth insight to the nature of the problem. Therefore, I strongly suggest for future researchers to incorporate qualitative study design for further comprehensive output on this area.

\section{Conclusion and Recommendation}

About one-fifth of students were clinically competent. Generally, this finding was lower than other recent previous studies conducted in Ethiopia so far. Providing orientation about assessment methods, encouraging students during clinical practice, clinical preceptor support, and students' confidence during conducting procedures during clinical practice was significantly associated with clinical practice competence.

Hence, the federal ministry of health should work closely with teaching institutions, health facilities, and other stakeholders to overcome those gaps. The clinical staff should encourage students during clinical practice and use different mechanisms to increase students' confidence while they are conducting the procedure. The institutions should allocate clinical preceptors in health facilities in which students are practicing and clinical instructors should briefly explain the assessment methods to their students.

\section{Abbreviation}

AOR, Adjusted odds ratio; COR, Crudes odds ratio; NGO, Non-Governmental organization; SD, standard deviation.

\section{Data Sharing Statement}

All the data of this study are available from the corresponding author upon request.

\section{Ethical Consideration}

Ethical clearance was obtained from the institutional ethical review board of Mekelle University, College of Health Sciences. An official letter of permission was written to each college before data collection. Participants were informed about the purpose, benefit, risk, confidentiality of the information and the voluntary nature of participation in the study. Data were collected after informed written consent was obtained from each participant that their data will be included in publications.

\section{Acknowledgment}

We are very grateful to Mekelle University for the financial support to this study and the department of midwifery for its mentorship. All study participants for their willingness in responding to our questionnaire.

\section{Author Contributions}

All authors made a significant contribution to the work reported, whether that is in the conception, study design, execution, acquisition of data, analysis and interpretation, or in all these areas; took part in drafting, revising or critically reviewing the article; gave final approval of the version to be published; have agreed on the journal to which the article has been submitted and agree to be accountable for all aspects of the work.

\section{Funding}

This work has been funded by Mekelle University for data collection purposes as for MSc thesis. Mekelle University College of Health Sciences, department of midwifery was involved in the project through monitoring and evaluation of the work from the beginning to the result submission. But this organization did not involve in designing, analysis, critical review of its intellectual content, preparation of the manuscript and the budget funded by this organization did not include for publication.

\section{Disclosure}

The authors declare that they have no conflicts of interest.

\section{References}

1. Lejonqvist G. Clinical competence, the core of Nursing education. Finland; 2018:12.

2. Bifftu BB, Dachew BA, Tiruneh BT, Kelkay MM, Bayu NH. Perceived clinical competence among undergraduate Nursing students at the University of Gondar and Bahir Dar University, Northwest Ethiopia. Adv Nurs. 2016;2016:4-5. doi:10.1155/2016/9294673

3. Edwards H, Smith S, Courtney M, Finlayson K. Impact of clinical placement location on nursing students competence and preparedness for practice. Nurse Educ Today. 2004;24(4):6-7. doi:10.1016/j. nedt.2004.01.003

4. UNFPA-ICM. Investing in Midwives and others with Midwifery skills to save the lives of mothers and newborns and improve their health; 2006:9-13.

5. Carr C, Fauveau V, Fogstad H, et al. The state of the world's Midwifery delivering saving health lives; 2011:5-7. 
6. Fikre R. Assessment of factors affecting clinical practice competency of undergraduate health science students in Hawassa University. Ann Clin Lab Res. 2016;4(1):1-7. doi:10.21767/23865180.100057

7. Berhanu F, Christopher H, Wuleta L, Agnes S. The health workforce in Ethiopia addressing the remaining challenges, World Bank. 2012:53-56.

8. Getie A. Clinical practice competency and associated factors among graduating Nursing students attending at Universities in Amhara Region. Res Sq. 2018;10(2):1-15.

9. Yigzaw T, Ayalew F, Kim Y, et al. How well does preservice education prepare Midwives for practice: competence assessment of Midwifery students at the point of graduation in Ethiopia. BMC Med Educ. 2015;130(15):1-3.

10. Tesfaye TS, Alemu W, Mekonen T. Perceived clinical practice competency and associated factors among undergraduate students of medicine and health science students at Dilla University. Adv Med Educ Pract. 2020;11:131. doi:10.2147/AMEP.S235823

11. Nursing and Midwifery Board of Ireland. Competence assessment tool; 2015:12-27.
12. Gemuhay HM, Kalolo A, Mirisho R, Chipwaza B, Nyangena E Factors affecting performance in clinical practice among preservice diploma Nursing students in Northern Tanzania. Hindawi Nurs Res Pract. 2019;2019:4-8.

13. Rani S, Hussain M, Afzal M, Gillani SA. The influence of personal characteristics of preceptor on professional grooming of Nursing students. Int J Med Res Health Sci. 2019;8(5):91-93.

14. Kajander-unkuri S. Nurse competence of graduating nursing students. Finland; 2015:47-50.

15. Rizany I, Tutik R, Hariyati S, Handayani H. Factors that affect the development of Nurses' competencies: a systematic review. Enferm Clin. 2018;28(1):155-156.

16. Atakro CA, Gross J. Preceptorship versus clinical teaching partnership: literature review and recommendations for implementation in Ghana. Adv Nurs. 2016;2016:2-4. doi:10.1155/2016/1919246

17. Romyn DM. Successful transition of the new graduate Nurse. Int J Nurs Educ. 2009;6:5-6.

18. Lena B, Ingeerd H, Carina S, Annika K. Developing of competence and confidence in Midwifery focus groups with Swedish Midwives. Women Birth. 2017;30(1):34-36.

\section{Publish your work in this journal}

Advances in Medical Education and Practice is an international, peerreviewed, open access journal that aims to present and publish research on Medical Education covering medical, dental, nursing and allied health care professional education. The journal covers undergraduate education, postgraduate training and continuing medical education including emerging trends and innovative models linking education, research, and health care services. The manuscript management system is completely online and includes a very quick and fair peer-review system. Visit http://www.dovepress.com/testimonials.php to read real quotes from published authors. 